STRUCTURAL BIOLOGY COMMUNICATIONS

ISSN 2053-230X

Received 21 March 2017

Accepted 30 June 2017

Edited by N. Sträter, University of Leipzig, Germany

Keywords: MCR-1; antibiotic resistance; colistin; MCR-2; polymixin.

PDB reference: MCR-2 catalytic domain, 5mx9

Supporting information: this article has supporting information at journals.iucr.org/f

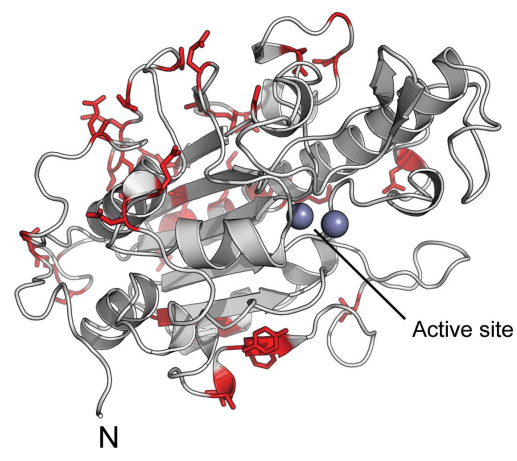

OPEN $\odot$ ACCESS

\section{$1.12 \AA$ resolution crystal structure of the catalytic domain of the plasmid-mediated colistin resistance determinant MCR-2}

\author{
Katie Coates, ${ }^{\text {a }}$ Timothy R. Walsh, ${ }^{\mathrm{b}}$ James Spencer ${ }^{\mathrm{a}}$ and Philip Hinchliffe ${ }^{\mathrm{a} *}$
}

${ }^{\mathbf{a}}$ School of Cellular and Molecular Medicine, University of Bristol, Bristol BS8 1TD, England, and ${ }^{\mathbf{b}}$ Department of Medical Microbiology and Infectious Disease, Cardiff Institute of Infection and Immunity, UHW Main Building, Heath Park Hospital, Cardiff CF14 4XN, Wales. *Correspondence e-mail: philip.hinchliffe@bristol.ac.uk

MCR-2 confers resistance to colistin, a 'last-line' antibiotic against extensively resistant Gram-negative pathogens. It is a plasmid-encoded phosphoethanolamine transferase that is closely related to MCR-1. To understand the diversity in the MCR family, the $1.12 \AA$ resolution crystal structure of the catalytic domain of MCR-2 was determined. Variable amino acids are located distant from both the di-zinc active site and the membrane-proximal face. The exceptionally high resolution will provide an accurate starting model for further mechanistic studies.

\section{Introduction}

The polymyxin colistin is a key 'last-resort' antibiotic used to treat infections by multidrug-resistant Gram-negative pathogens (Biswas et al., 2012; Karaiskos et al., 2017). The positively charged cyclic peptide of colistin binds to the negatively charged lipid A headgroup, with the hydrophobic tail inserting into, and disrupting, the outer membrane (Clausell et al., 2007; Wiese et al., 2003). A key colistin resistance mechanism is the production of MCR-1 (Liu et al., 2016), a plasmid-encoded phosphoethanolamine transferase that has disseminated worldwide. It is found in clinical strains of Escherichia coli and Klebsiella pneumoniae (Liu et al., 2016), and in bacteria producing other resistance determinants, such as carbapenemases (Mediavilla et al., 2016; Haenni et al., 2016), which can result in essentially untreatable bacterial infections.

MCR-1 catalyses the transfer of positively charged phosphoethanolamine onto lipid A, which is subsequently incorporated into the outer membrane, reducing the net negative charge and preventing colistin binding (Hinchliffe et al., 2017; Liu et al., 2016). It is an integral, metal-dependent innermembrane protein, with a large periplasmic domain containing the catalytic centre and the conserved Thr285 that is likely to act as the acceptor for the phosphoethanolamine group during the transfer reaction (Hinchliffe et al., 2017). We recently described two crystal structures of the MCR-1 catalytic domain (MCR-1 ${ }^{\mathrm{CD}}$ ), revealing the presence of one (PDB entry 5lrn; MCR-1 ${ }^{\text {5LRN }}$ ) or two (PDB entry 5lrm; MCR-1 $1^{\text {5LRM }}$ ) zinc ions in the active site (Hinchliffe et al., 2017), with the proposed catalytic Thr285 phosphorylated or not phosphorylated, respectively. Additional MCR-1 ${ }^{\mathrm{CD}}$ structures have been reported: two with phosphorylated Thr285 and crystallized from conditions with a nonphysiologically high zinc content [PDB entries 5gov (MCR-1 ${ }^{5 \mathrm{GOV}}$; Hu et al., 2016) and 5k4p (MCR-1 ${ }^{5 \mathrm{~K} 4 \mathrm{P}}$; Stojanoski et al., 2016)], and consequently 
containing additional zinc ions, and one with two active-site zinc ions and both phosphorylated and nonphosphorylated Thr285 (PDB entry 5grr; MCR-1 ${ }^{5 \mathrm{GRR}}$; Ma et al., 2016). More recently, the full-length, detergent-solubilized crystal structure of an MCR homologue (EptA; 36\% sequence identity to MCR-2) was solved (Anandan et al., 2017) with a single zinc ion, a nonphosphorylated Thr285 and a bound molecule of dodecyl maltoside (DDM) in the active site. This full-length structure confirmed the prediction (Hinchliffe et al., 2017) that the active site is proximal to the membrane.

Two genes closely related to $m c r-1$ have also been identified. Firstly, mcr1.2, containing a Gln3Leu substitution, was found in a $K$. pneumoniae strain (Di Pilato et al., 2016). Secondly, mcr-2 was detected in colistin-resistant E. coli isolated from porcine and bovine samples, with a higher prevalence than $m c r-1$ in the porcine samples (Xavier et al.,

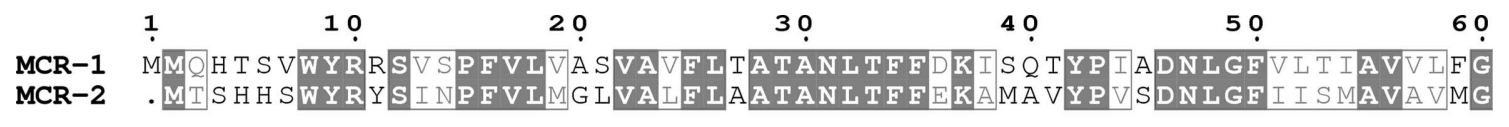

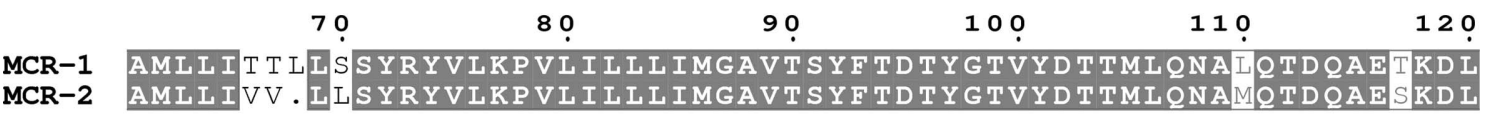

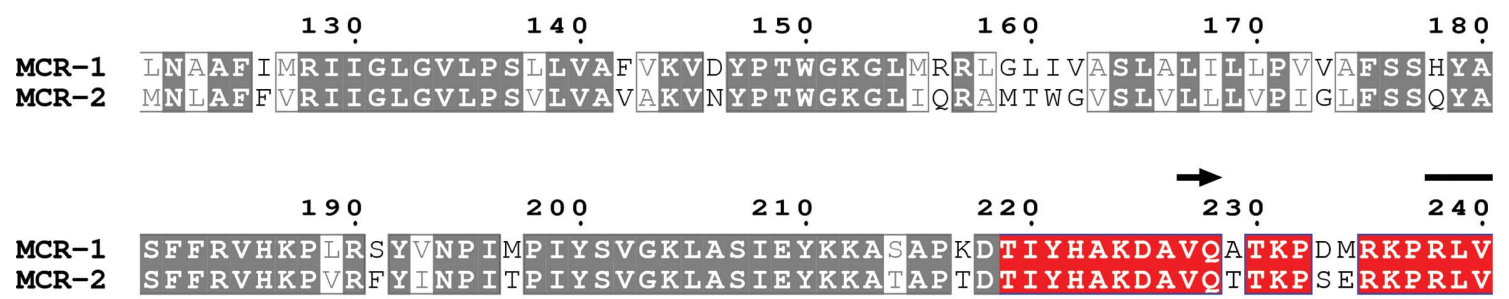

MCR-2 STFRVHRPVRFYINPITPIYSVGKLASIEYKKATAPTDTIYHAKDAVOTTKPSERKPRLV

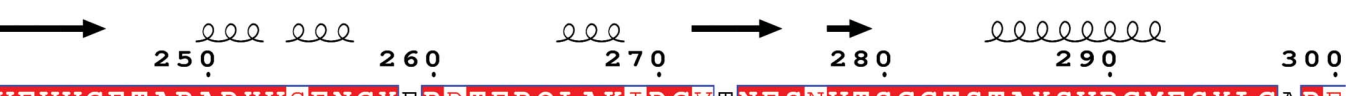

MCR-1 VFVVGETARADHVSFNGYERDTFPOLAKIDGVTNESNVTSCGTSTAYSVPCMESYLGADE

MCR-2 VFVVGETARADHVQFNGYGRETFPQLAKVDGLANFSQVTSCGTSTAYSVPCMFSYLGQDD

$\Delta$

$\operatorname{lecel}_{310}$ lebele ${ }_{320} \longrightarrow 30$

34 ọ $\stackrel{\Delta}{\longrightarrow}$ ?

360

MCR-1 YDVDTAKYQENVLDTLDRLGVSILWRDNNSD K GVMDKLPKAOFADYKSATNNAICNTNP

MCR-2 YDVDTAKYQENVLDTLDRLGVGILWRDNNSDSKGVMDKLPATOYFDYKSATNNTICNTNP

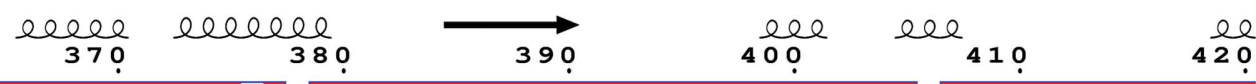

$\begin{array}{ll}\text { MCR-1 } & \text { YNECRDVGMLVGLDDFVAANNGKDMLIMLHQMGNHGPAYFRRYDEKFAKFTPVCEGNELA } \\ \text { MCR-2 } & \text { YNECRDVGMLVGLDDYVANNGKDLIMLHOMGNHGPAYFRYDEGFAFTPVCEGNEA }\end{array}$

$\Delta$

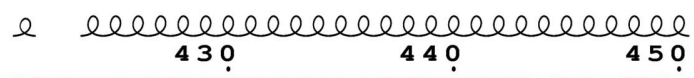

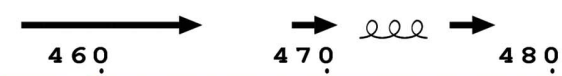

MCR-1 KCEHQSLINAY DNALLATDDFIAQS IQWLLTHSNAYDVSMLYVSDHGESLGENGVYLHGM

MCR-2 KCEHOSLINAYDNALLATDDFIAKSIDWLKTHEANYDVAMLYVSDHGES L GENGVYLHGM

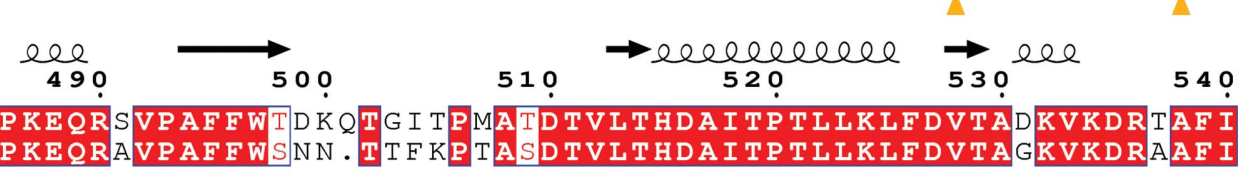

MCR-1 R

MCR-2 Q

Figure 1

Sequence alignment of MCR-1 (541 residues) and MCR-2 (538 residues). Strictly conserved residues are boxed in white on a red background and highly conserved residues are boxed in red on a white background. The putative membrane domain is greyed out (residues 1-218). Secondary structure is indicated above based on the MCR- $2^{\mathrm{CD}}$ crystal structure. Residues where mutations reduce MCR-1 activity to basal levels are indicated by red triangles, and residues that are important to MCR-1 activity (i.e. mutation significantly reduces but does not abolish activity) are indicated by yellow triangles. 
Table 1

Macromolecule-production information.

Lower-case letters in the primers indicate overlap with pOPIN-F for In-Fusion cloning. The $\mathrm{His}_{6}$ tag is in shown in italics and the $3 \mathrm{C}$ protease cleavage site is underlined in the construct sequence.

\section{Source organism \\ DNA source}

Forward primer

Reverse primer

Cloning vector

Expression vector

Complete amino-acid sequence of the construct produced
Expression host

\begin{abstract}
E. coli
Synthetic codon-optimized gene aagttctgtttcagggeccgACCATCTATCACGCCAAAGATGCG

atggtctagaaagctttaCTGGATAAACGCAGCACGGTC

pEX-A2

pOPIN-F

E. coli SoluBL21

MAHHHHHHSSGLEVLGPTIYHAKDAVQTTKPSERKPRLVVFVVGETARADHVQFNGYGRETFPQLAKVDGLANFSQVTSCGTSTAYSVPCMFSYLGQDDYDVDTAKYQENVLDTLDRLGVGILWRDNNSDSKGVMDKLPATQYFDYKSATNNTICNTNPYNECRDVGMLVGLDDYVSANNGKDMLIMLHQMGNHGPAYFKRYDEQFAKFTPVCEGNELAKCEHQSLINAYDNALLATDDF IAKSIDWLKTHEANYDVAMLYVSDHGESLGENGVYLHGMPNAFAPKEQRAVPAFFWSNNTTFKPTASDTVLTHDAITPTLLKLFDVTAGKVKDRAAFIQ
\end{abstract}

2016). $m c r-2$ is harboured on a plasmid (IncX4) with a high transfer frequency that appears to lack a fitness cost to the host and can harbour MCR-1 (Fernandes et al., 2016; Li, Yang et al., 2016) alongside extended-spectrum $\beta$-lactamases such as TEM and CTX-M (Li, Xie et al., 2016; Falgenhauer et al., 2016; Lo et al., 2014). MCR-2 (538 residues) is $81 \%$ identical to MCR-1 (Fig. 1), with 101 amino-acid substitutions (61 in the transmembrane domain and 40 in the catalytic domain) and three deletions (Met1 and Leu68 in the transmembrane domain and Gln501 in the catalytic domain; MCR-1 numbering is used throughout). Residues previously identified as essential (Glu246, His395 and the phosphorylation site Thr285) or important (Lys333, Glu468 and His478) for MCR-1 activity (Hinchliffe et al., 2017) are strictly conserved in MCR-2 (red or yellow triangles, respectively, in Fig. 1), indicating a likely identical catalytic mechanism. To understand MCR diversity, we have solved the crystal structure of the MCR-2 catalytic domain (residues 217-538; MCR-2 ${ }^{\mathrm{CD}}$ ), which is $87 \%$ identical to $\mathrm{MCR}-1^{\mathrm{CD}}$.

\section{Materials and methods}

\subsection{Macromolecule production}

To facilitate structural studies, we removed the transmembrane domain and synthesized $m c r-2$ codons 217-538 (Eurofins), and subcloned them into pOPIN-F (Berrow et al., 2007) using the primers in Table 1, resulting in plasmid pOPINFMCR2 $2^{217-538}$ encoding N-terminally $\mathrm{His}_{6}$-tagged protein (Table 1). The protein was purified as for $\mathrm{MCR}-1^{\mathrm{CD}}$ (Hinchliffe et al., 2017). Briefly, E. coli SoluBL21 cells bearing pOPINF-MCR2 $2^{217-538}$ were induced at $18^{\circ} \mathrm{C}$ with IPTG overnight and the protein was purified using Ni-NTA affinity chromatography. The buffers contained $100 \mu M \quad \mathrm{ZnCl}_{2}$ throughout, and the tag was removed by $3 \mathrm{C}$ protease cleavage and captured on Ni-NTA resin. Protein was loaded onto a
Table 2

Crystallization.

\begin{tabular}{ll}
\hline Method & Sitting-drop vapour diffusion \\
Plate type & MRC 2-drop 96-well \\
Temperature (K) & 291 \\
Protein concentration $\left(\mathrm{mg} \mathrm{ml}^{-1}\right)$ & 15 \\
Buffer composition of protein & $50 \mathrm{mM} \mathrm{HEPES}$ pH 7.5, 150 mM NaCl, \\
$\quad$ solution & $100 \mu M \mathrm{ZnCl}_{2}$ \\
Composition of reservoir solution & $0.1 \mathrm{MSCN}, 30 \%$ PEG 2000 MME \\
Volume and ratio of drop & $0.4 \mu \mathrm{l}$ protein solution, $0.2 \mu \mathrm{l}$ reservoir \\
& solution \\
Volume of reservoir $(\mu \mathrm{l})$ & 50 \\
\hline
\end{tabular}

Table 3

Data collection and processing.

Values in parentheses are for the outer shell.

\begin{tabular}{ll}
\hline Diffraction source & Beamline I04, DLS \\
Wavelength $(\AA)$ & 0.97949 \\
Temperature $(\mathrm{K})$ & 100 \\
Detector & PILATUS 6M-F \\
Crystal-to-detector distance $(\mathrm{mm})$ & 187.63 \\
Rotation range per image $\left(^{\circ}\right)$ & 0.2 \\
Total rotation range $\left({ }^{\circ}\right)$ & 360 \\
Exposure time per image (s) & 0.1 \\
Space group & $P 2_{1} 2_{1} 2_{1}$ \\
$a, b, c(\AA)$ & $44.82,53.31,117.51$ \\
$\alpha, \beta, \gamma\left({ }^{\circ}\right)$ & $90,90,90$ \\
Mosaicity $\left({ }^{\circ}\right)$ & 0.133 \\
Resolution range $(\AA)$ & $58.75-1.12(1.14-1.12)$ \\
Total No. of reflections & $1276800(31833)$ \\
No. of unique reflections & $108781(5133)$ \\
Completeness $(\%)$ & $99.8(96.8)$ \\
Multiplicity & $11.7(6.2)$ \\
$\langle I / \sigma(I)\rangle$ & $20.4(3.4)$ \\
$R_{\text {r.i.m. }}$ & $0.017(0.192)$ \\
$C C_{1 / 2}$ & $1.000(0.879)$ \\
Overall $B$ factor from Wilson plot $\left(\AA^{2}\right)$ & 8.361 \\
\hline
\end{tabular}

Superdex 75 size-exclusion column equilibrated in $50 \mathrm{~m} M$ HEPES pH 7.5, $150 \mathrm{~m} M \mathrm{NaCl}, 100 \mu M \mathrm{ZnCl}_{2}$. As for MCR-1 ${ }^{\mathrm{CD}}$ (Hinchliffe et al., 2017; Ma et al., 2016), MCR-2 ${ }^{\mathrm{CD}}$ eluted from the Superdex 75 column as a monomer. Peak fractions were concentrated to $15 \mathrm{mg} \mathrm{ml}^{-1}$ by centrifugation.

\subsection{Crystallization}

Crystallization screens were conducted in MRC 2-drop 96-well sitting-drop plates using commercially available sparse-matrix screens (JCSG-plus, ProPlex, Structure Screen $1+2$, Morpheus and PACT Premier from Molecular Dimensions). Crystals were obtained by mixing $0.4 \mu \mathrm{l}$ protein solution $\left(15 \mathrm{mg} \mathrm{ml}^{-1}\right)$ with $0.2 \mu \mathrm{l}$ reservoir solution $(0.1 \mathrm{M}$ KSCN, 30\% PEG $2000 \mathrm{MME}$ ) and equilibrating against $50 \mu \mathrm{l}$ reservoir solution (Table 2), were harvested in reservoir plus $25 \%$ glycerol and were flash-cooled in liquid nitrogen.

\subsection{Data collection and processing}

X-ray data (Table 3) were collected at $100 \mathrm{~K}$ on beamline I04 at Diamond Light Source (DLS), UK, integrated in DIALS (Waterman et al., 2016) and scaled using AIMLESS (Evans \& Murshudov, 2013) in the CCP4 suite (Winn et al., 2011). 


\subsection{Structure solution and refinement}

Crystallographic phases were solved using Phaser (McCoy et al., 2007) with MCR-1 ${ }^{\mathrm{CD}}$ (PDB entry 5lrn) as the starting model. Variable amino acids were altered to the MCR-2 sequence and the model was completed by iterative rounds of manual model building and refinement in Coot (Emsley et al., 2010) and PHENIX (Adams et al., 2010). B factors were refined anisotropically, except for $\mathrm{H}$ atoms and water molecules, which were refined isotropically. Structure validation was assisted by MolProbity (Chen et al., 2010) and PHENIX. Details of the refinement statistics are shown in Table 4. Atomic coordinates and structure factors have been deposited in the Protein Data Bank (PDB entry 5mx9).

\section{Results and discussion}

The overall MCR $-2^{\mathrm{CD}}$ fold contains three disulfide bonds and is essentially identical to that of MCR-1 ${ }^{5 L R N}$ (root-meansquare deviation of $0.54 \AA$ over $314 \mathrm{C}^{\alpha}$ atoms calculated using PDBeFold; Krissinel \& Henrick, 2004; Fig. 2a). A single residue (Ser330) is a Ramachandran plot outlier, with $\varphi$ and $\psi$ values of -165.9 and $-82.4^{\circ}$, respectively. This residue is sterically strained by forming a hydrogen bond to Asn329, and is also a Ramachadran plot outlier in all other MCR-1 structures. Solvent-accessible loops are largely unperturbed, although loop 411-424 shifts $\sim 4 \AA$ between MCR-1 ${ }^{5 \mathrm{GRR}}$ and MCR $-2^{\mathrm{CD}}$. Based on comparison with the more distantly related phosphoethanolamine transferases LptA (Wanty et al., 2013) and EptC (Fage et al., 2014), which have 36 and 35\% sequence identity to MCR-2, respectively, loop 348-365 of MCR-2 (Fig. 2a) was suggested to be flexible and in an open conformation for substrate entry (Ma et al., 2016). However, it makes significant crystal contacts and is in similar conformations (maximum movement of $1.5 \AA$ ) in all physiologically relevant MCR structures, with low $B$ factors in MCR-2 ${ }^{\mathrm{CD}}$ $\left(11.6 \AA^{2}\right)$. Differences in this loop compared with LptA and EptC are likely to be because the loop is longer in MCR proteins (18 residues compared with 15 and four for LptA and EptC, respectively), and may not be relevant for substrate entry. The variable amino acids of MCR-2 compared with MCR-1 are distant from both the active site and the relatively flat, proposed membrane-proximal face of the molecule (Fig. 2b). Indeed, most are located on the surface, likely facing the periplasm, with the exception of Ser459Ala on the central $\beta$-sheet. The Gln501 deletion results in a periplasmic exposed loop (Fig. 2b), rather than helical turn as in MCR-1, but is also distant from the active site. The effect of these variable amino acids on the activity is therefore likely to be minimal. However, this requires in vitro verification once both recombinant full-length enzyme is available and an assay with a suitable substrate has been developed.

MCR-2 ${ }^{\mathrm{CD}}$ contains a nonphosphorylated Thr285 and clear density indicating two metal ions in the active site, modelled as zinc based on the presence of $100 \mu M$ zinc in the purification buffers and homology to MCR-1, in which zinc was identified based on X-ray fluorescence scans and density functional
Table 4

Structure refinement.

Values in parentheses are for the outer shell.

\begin{tabular}{|c|c|}
\hline Resolution range $(\AA)$ & $48.548-1.120$ \\
\hline Completeness (\%) & 99.8 \\
\hline No. of reflections, working set & 108679 \\
\hline No. of reflections, test set & 5480 \\
\hline Final $R_{\text {cryst }}$ & 0.1334 \\
\hline Final $R_{\text {free }}$ & 0.1453 \\
\hline \multicolumn{2}{|l|}{ No. of non-H atoms } \\
\hline Protein & 2565 \\
\hline Zinc & 2 \\
\hline Solvent & 437 \\
\hline Total & 3004 \\
\hline \multicolumn{2}{|l|}{ R.m.s. deviations } \\
\hline Bonds $(\AA)$ & 0.008 \\
\hline Angles $\left({ }^{\circ}\right)$ & 1.382 \\
\hline \multicolumn{2}{|l|}{ Average $B$ factors $\left(\AA^{2}\right)$} \\
\hline Protein & 11.57 \\
\hline Zinc & 10.48 \\
\hline Solvent & 25.79 \\
\hline \multicolumn{2}{|l|}{ Ramachandran plot } \\
\hline Favoured regions (\%) & 97.86 \\
\hline Additionally allowed (\%) & 1.83 \\
\hline Outliers (\%) & 0.31 \\
\hline
\end{tabular}

theory calculations (Fig. 3a). As for $\mathrm{Zn} 1$ in MCR-1, Zn1 in MCR-2 is coordinated by Glu246, Thr285 and Asp465 (all with a coordination distance of $1.92 \AA)$ and His466 (2.04 $\AA$ ) in a tetrahedral geometry (Supplementary Table S1). Although the Zn1 coordination distances are shorter in MCR-2 compared with MCR-1 (Supplementary Table S1; Hinchliffe et al., 2017), there are no other structural differences around the $\mathrm{Zn} 1$ site, further underlying the importance of $\mathrm{Zn} 1$ to enzyme function. Similar to as in MCR-1 ${ }^{5 \mathrm{LRM}}$ (Fig. $3 b$ ), $\mathrm{Zn} 2$ in MCR-2 forms a tetrahedral geometry and is coordinated by His395, His478, a tightly bound water molecule ( $B$ factor of $11.97 \AA^{2}$ ) and Glu405 from a symmetry-related molecule. In MCR-1 ${ }^{5 L R M}$ this latter coordination is instead provided by Glu300 owing to substantially different crystal packing. This further highlights the likely lack of physiological relevance of the MCR dimer (Ma et al., 2016; Hinchliffe et al., 2017) but suggests that the second zinc site can tolerate varying coordinating ligands. The $\mathrm{Zn} 2$ site is unoccupied in the two nonphysiological, high zinccontent MCR-1 structures reported previously (MCR $-1^{5 \mathrm{GOV}}$ and $\left.\mathrm{MCR}-1^{5 \mathrm{~K} 4 \mathrm{P}}\right)$. MCR-1 $1^{5 \mathrm{GRR}}$ is similar but contains an additional water molecule bridging $\mathrm{Zn} 1$ and $\mathrm{Zn} 2$ (Wat2; Fig. $3 c$ ). However, this water molecule has a high $B$ factor $\left(51.5 \AA^{2}\right)$, relatively low occupancy $(0.8)$ and little corresponding electron density and is not in any other MCR structure, suggesting that it is nonphysiological and should not be considered in mechanistic discussions.

Superposition with the full-length MCR homologue EptA (root-mean-square deviation of $0.660 \AA$ over $213 \mathrm{C}^{\alpha}$ catalytic domain residues; Fig. $3 d$, left) reveals close structural similarity between the two, as noted previously on comparison of the catalytic domains MCR-1 ${ }^{\mathrm{CD}}$ and EptA ${ }^{\mathrm{CD}}$ (Hinchliffe et al., 2017; Wanty et al., 2013). Indeed, despite differences in zinc occupancy (two zincs in MCR-2 and one in EptA), and the presence of DDM in EptA, the conserved active-site residues adopt similar conformations, except for small differences of 
the conserved His 395 and His478 residues that coordinate $\mathrm{Zn} 2$ in MCR-2 ${ }^{\mathrm{CD}}$ (Fig. 3d, right). In EptA, His478 coordinates a DDM molecule, suggesting a possible role for these residues in positioning the substrate rather than binding a second zinc ion. However, it cannot be ruled out that physiological substrates (i.e. lipid A or phosphatidylethanolamine) could replace the Glu300/Glu405-Zn2 coordination in recruiting a second zinc ion during the mechanism (Wanty et al., 2013).

The physiological relevance of the second zinc site has yet to be established, although it has now been observed in three

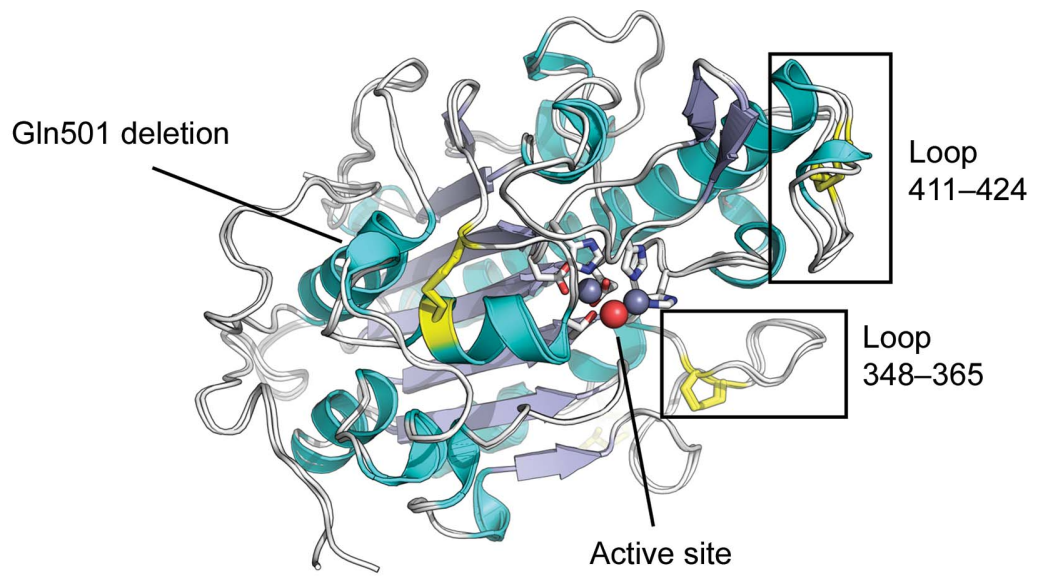

(a)
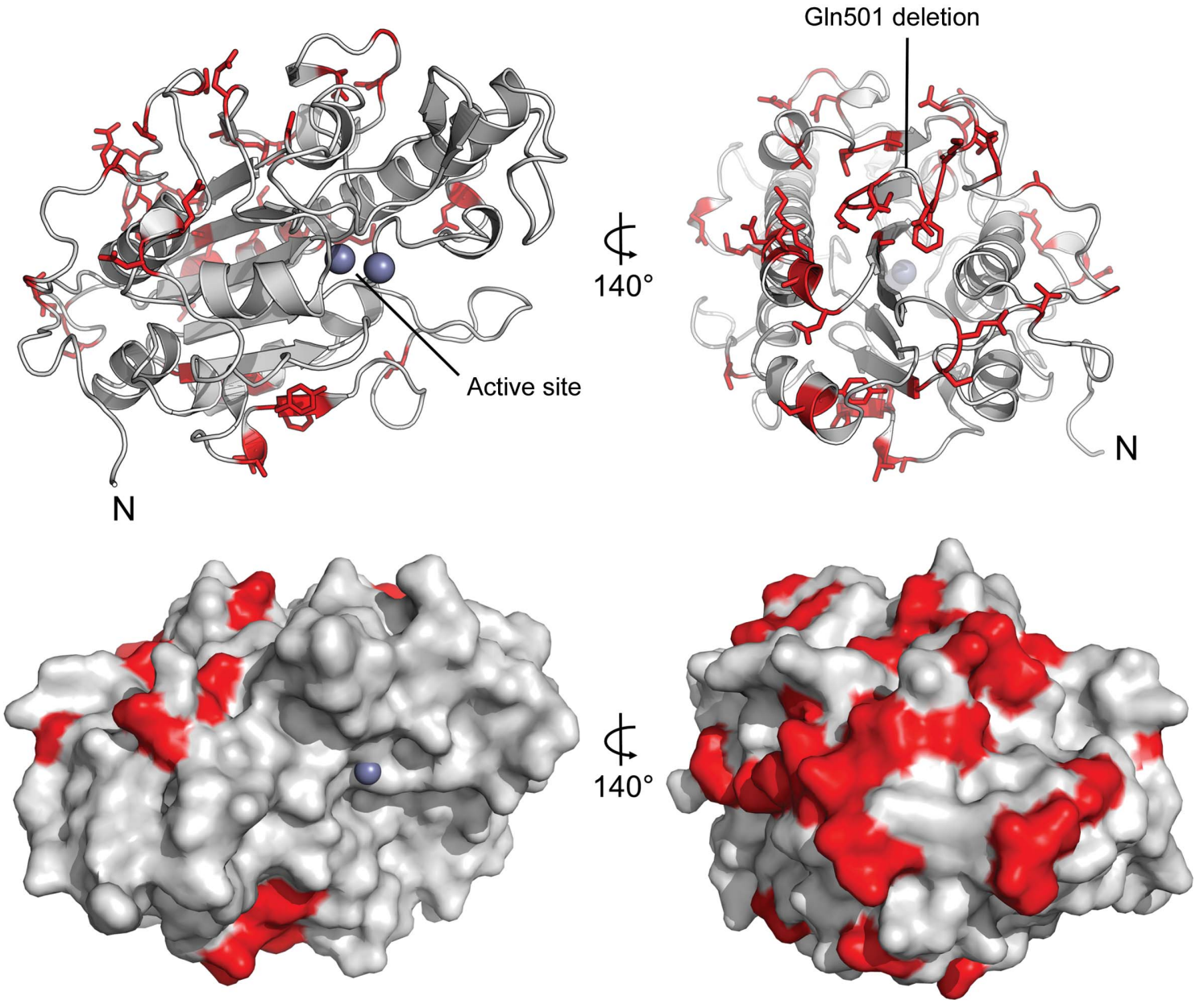

(b)

Figure 2

Structural comparisons of MCR-1 and MCR-2. (a) Alignment of MCR-1 $1^{5 \mathrm{LRN}}$ and MCR-2 ${ }^{\mathrm{CD}}$, both coloured by secondary structure (loops are in grey, $\alpha$-helices in cyan and $\beta$-sheets in blue). The MCR-2 active site is shown ( $\mathrm{Zn}$ spheres are in grey, waters are shown as red spheres and zinc-coordinating residues are shown as sticks). (b) Positions of variable amino acids (red) in MCR-2. The di-zinc (grey spheres) active site (labelled) is located on the putative membrane-proximal face. Top: two views of MCR-2 rotated $140^{\circ}$, with variable amino acids shown as sticks. Bottom: MCR-2 surface view, with orientations as in $(a)$. 


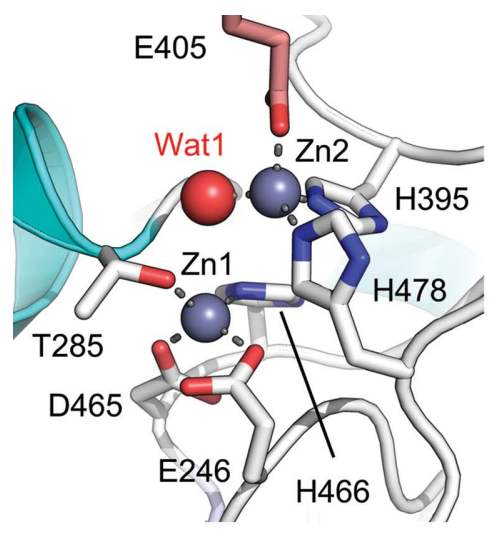

MCR-2

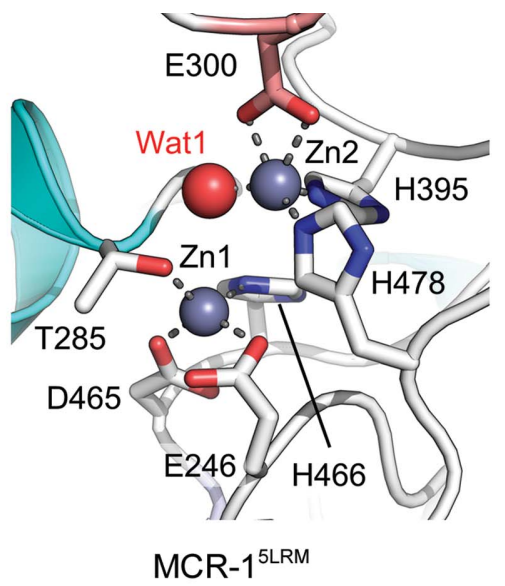

(b)

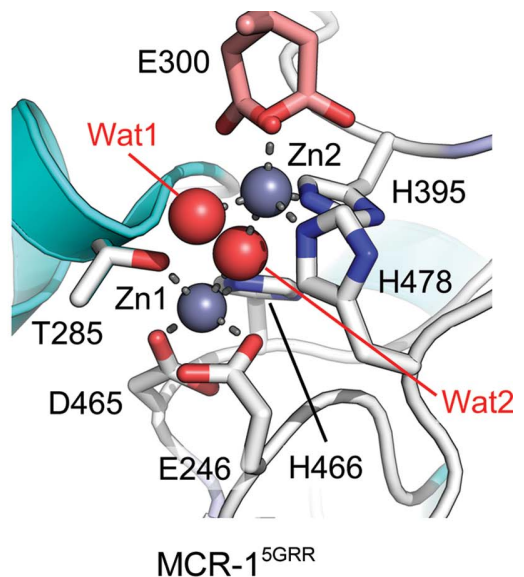

(c)

MCR-2

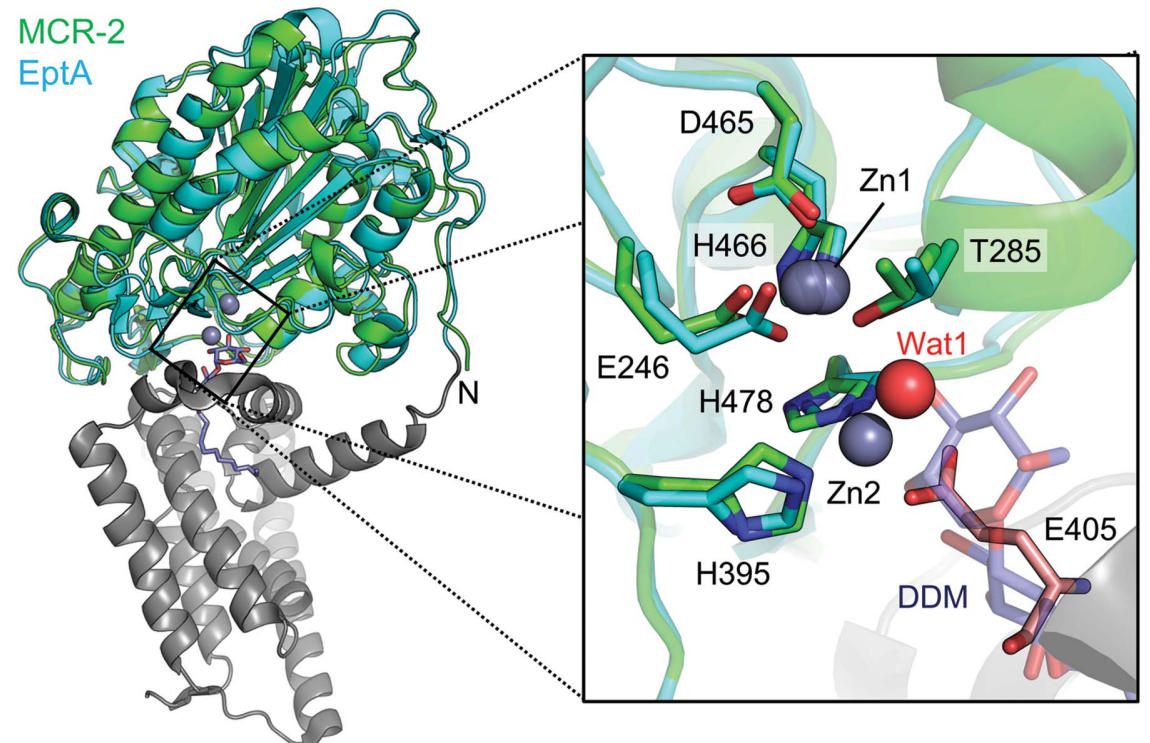

(d)

Figure 3

Comparison of MCR-2 with di-zinc MCR-1 and full-length EptA. (a) A close-up view of the MCR-2 di-zinc active site. Representations are as in Fig. 2. Residues from symmetry-related molecules are coloured light red. (b) MCR-1 ${ }^{5 \mathrm{LRM}}$ active site. (c) MCR-1 ${ }^{5 \mathrm{GRR}}$ active site. (d) Superposition of the MCR-2 catalytic domain with full-length EptA. The catalytic domains of MCR-2 (green) and EptA (cyan; PDB entry 5fgn; Anandan et al., 2017) are superposed. The membrane domain of EptA is coloured grey; zinc ions are shown as grey spheres and bound DDM as purple sticks. Left: overall view with the N-terminus of MCR-2 labelled. Right: close-up of the active site with zinc-coordinating residues shown as sticks and the Zn2-coordinating water shown as a red sphere. MCR-2 Glu405 from a symmetry-related molecule is coloured pink.

MCR crystal structures. Our density functional theory calculations (Hinchliffe et al., 2017) suggest a two-zinc mechanism to be feasible for MCR-1, although a one-zinc mechanism was tentatively more favourable. Resolving this issue will require accurate and detailed mechanistic and computational studies of phosphoethanolamine transfer by the MCR family of enzymes, the latter of which will be greatly facilitated by the exceptionally high resolution of the current structure. The MCR-2 ${ }^{\mathrm{CD}}$ structure also indicates that amino-acid mutations on the periplasmic facing surface of MCR-1 are well tolerated. This, together with the wide geographic distribution of MCR-1 and the intense current research in this area, makes it likely that further clinical MCR variants will be identified in due course. Thus, achieving full understanding of mobile colistin resistance will require consideration, including structural and biochemical characterization, of family members beyond
MCR-1. The current structure represents a first step towards this goal.

\section{Acknowledgements}

We thank Diamond Light Source for access to beamline I04 (proposal No. MX12342) that contributed to the results presented here, and the staff of the Diamond Macromolecular Crystallography Village for their help.

\section{Funding information}

This work was supported by a grant from the UK Medical Research Council (MR/P007295/1) to TRW and JS.

\section{References}

Adams, P. D. et al. (2010). Acta Cryst. D66, 213-221. 
Anandan, A., Evans, G. L., Condic-Jurkic, K., O’Mara, M. L., John, C. M., Phillips, N. J., Jarvis, G. A., Wills, S. S., Stubbs, K. A., Moraes, I., Kahler, C. M. \& Vrielink, A. (2017). Proc. Natl Acad. Sci. USA, 114, 2218-2223.

Berrow, N. S., Alderton, D., Sainsbury, S., Nettleship, J., Assenberg, R., Rahman, N., Stuart, D. I. \& Owens, R. J. (2007). Nucleic Acids Res. 35, e45.

Biswas, S., Brunel, J.-M., Dubus, J.-C., Reynaud-Gaubert, M. \& Rolain, J.-M. (2012). Expert Rev. Anti Infect. Ther. 10, 917-934.

Chen, V. B., Arendall, W. B., Headd, J. J., Keedy, D. A., Immormino, R. M., Kapral, G. J., Murray, L. W., Richardson, J. S. \& Richardson, D. C. (2010). Acta Cryst. D66, 12-21.

Clausell, A., Garcia-Subirats, M., Pujol, M., Busquets, M. A., Rabanal, F. \& Cajal, Y. (2007). J. Phys. Chem. B, 111, 551-563.

Di Pilato, V., Arena, F., Tascini, C., Cannatelli, A., Henrici De Angelis, L., Fortunato, S., Giani, T., Menichetti, F. \& Rossolini, G. M. (2016). Antimicrob. Agents Chemother. 60, 5612-5615.

Emsley, P., Lohkamp, B., Scott, W. G. \& Cowtan, K. (2010). Acta Cryst. D66, 486-501.

Evans, P. R. \& Murshudov, G. N. (2013). Acta Cryst. D69, 12041214.

Fage, C. D., Brown, D. B., Boll, J. M., Keatinge-Clay, A. T. \& Trent, M. S. (2014). Acta Cryst. D70, 2730-2739.

Falgenhauer, L., Waezsada, S. E., Yao, Y., Imirzalioglu, C., Käsbohrer, A., Roesler, U., Michael, G. B., Schwarz, S., Werner, G., Kreienbrock, L. \& Chakraborty, T. (2016). Lancet Infect. Dis. 16, 282-283.

Fernandes, M. R., McCulloch, J. A., Vianello, M. A., Moura, Q., Perez-Chaparro, P. J., Esposito, F., Sartori, L., Dropa, M., Matte, M. H., Lira, D. P., Mamizuka, E. M. \& Lincopan, N. (2016). Antimicrob. Agents Chemother. 60, 6415-6417.

Haenni, M., Poirel, L., Kieffer, N., Chatre, P., Saras, E., Metayer, V., Dumoulin, R., Nordmann, P. \& Madec, J.-Y. (2016). Lancet Infect. Dis. 16, 281-282.
Hinchliffe, P. et al. (2017). Sci. Rep. 7, 39392.

Hu, M., Guo, J., Cheng, Q., Yang, Z., Chan, E. W. C., Chen, S. \& Hao, Q. (2016). Sci. Rep. 6, 38793.

Karaiskos, I., Souli, M., Galani, I. \& Giamarellou, H. (2017). Expert Opin. Drug Metab. Toxicol. 13, 59-71.

Krissinel, E. \& Henrick, K. (2004). Acta Cryst. D60, 2256-2268.

Li, A., Yang, Y., Miao, M., Chavda, K. D., Mediavilla, J. R., Xie, X., Feng, P., Tang, Y.-W., Kreiswirth, B. N., Chen, L. \& Du, H. (2016). Antimicrob. Agents Chemother. 60, 4351-4354.

Li, R., Xie, M., Zhang, J., Yang, Z., Liu, L., Liu, X., Zheng, Z., Chan, E. W.-C. \& Chen, S. (2016). J. Antimicrob Chemother. 72, 393-401.

Liu, Y.-Y. et al. (2016). Lancet Infect. Dis. 16, 161-168.

Lo, W.-U., Chow, K.-H., Law, P. Y., Ng, K.-Y., Cheung, Y.-Y., Lai, E. L. \& Ho, P.-L. (2014). J. Med. Microbiol. 63, 835-840.

Ma, G., Zhu, Y., Yu, Z., Ahmad, A. \& Zhang, H. (2016). Sci. Rep. 6, 39540.

McCoy, A. J., Grosse-Kunstleve, R. W., Adams, P. D., Winn, M. D., Storoni, L. C. \& Read, R. J. (2007). J. Appl. Cryst. 40, 658-674.

Mediavilla, J. R., Patrawalla, A., Chen, L., Chavda, K. D., Mathema, B., Vinnard, C., Dever, L. L. \& Kreiswirth, B. N. (2016). MBio, 7, e01191-16.

Stojanoski, V., Sankaran, B., Prasad, B. V., Poirel, L., Nordmann, P. \& Palzkill, T. (2016). BMC Biol. 14, 81.

Wanty, C., Anandan, A., Piek, S., Walshe, J., Ganguly, J., Carlson, R. W., Stubbs, K. A., Kahler, C. M. \& Vrielink, A. (2013). J. Mol. Biol. 425, 3389-3402.

Waterman, D. G., Winter, G., Gildea, R. J., Parkhurst, J. M., Brewster, A. S., Sauter, N. K. \& Evans, G. (2016). Acta Cryst. D72, 558-575.

Wiese, A., Gutsmann, T. \& Seydel, U. (2003). J. Endotoxin Res. 9, 67-84.

Winn, M. D. et al. (2011). Acta Cryst. D67, 235-242.

Xavier, B. B., Lammens, C., Ruhal, R., Kumar-Singh, S., Butaye, P., Goossens, H. \& Malhotra-Kumar, S. (2016). Euro Surveill. 21, https://doi.org/10.2807/1560-7917.ES.2016.21.27.30280. 